\title{
Diversitywashing: as marcas e suas (in)coerências expressivas
}

\section{Diversitywashing: brands and their expressive (in) coherences}

Fernanda Carreral

Chalini Torquato ${ }^{2}$

Resumo: Na problemática sobre discursos midiatizados e representação de corpos e sujeitos diversos, é perceptível a necessidade de aprofundamento do debate sobre os impactos e os limites das iniciativas publicitárias. Este trabalho busca, portanto, debruçar-se sobre o conceito de diversitywashing, entendendo que muitas estratégias de marca camuflam práticas inconsistentes, sobretudo em relação às rotinas produtivas da publicidade e aos rastros de estereótipos imagéticos e textuais, que revelam uma contradição daquilo que expõem discursivamente. Assim, propõe-se aqui discutir sobre as demandas contemporâneas acerca da relação entre mídia e diversidade, conceitualizando a noção de diversitywashing e apontando para seis traços comuns desta prática (representações inadequadas; atribuição de neutralidade; bastidores contraditórios; diversidade limitada; comportamentos incoerentes; e vida passada) à luz de pressupostos teóricos sobre performatização de si, gerenciamento de impressões e coerência expressiva.

Palavras-chave: diversitywashing; diversidade; publicidade; marca; coerência expressiva.

Abstract: In the problem of media discourses and representation of diverse bodies and subjects, the need to deepen the debate on the impacts and limits of advertising initiatives is perceptible. This work seeks, therefore, to focus on the

1 Universidade Federal do Rio de Janeiro (UFRJ). Rio de Janeiro, RJ, Brasil. https://orcid.org/0000-0001-5024-0860.E-mail: fernanda.carrera@eco.ufrj.br 2 Universidade Federal do Rio de Janeiro (UFRJ). Rio de Janeiro, RJ, Brasil. https://orcid.org/0000-0003-2021-7795. E-mail: chalinibarros@gmail.com 
concept of diversitywashing, understanding that many brand strategies camouflage inconsistent practices, especially in relation to the productive routines of advertising and the traces of image and textual stereotypes, which reveal a contradiction of what they discursively expose. Thus, it is proposed here to discuss the contemporary demands on the relationship between media and diversity, conceptualizing the notion of diversitywashing and pointing to six common features of this practice (inadequate representations; attribution of neutrality; contradictory backstage; limited diversity; incoherent behaviors; and past life) in light of theoretical assumptions about self-performatization, management of impressions and expressive coherence.

Keywords: diversitywashing; diversity; advertising; brand; expressive coherence. 


\section{Introdução}

No final da década de 1990 e início dos anos 2000, enquanto os impactos ambientais do aquecimento global e os desequilíbrios ecológicos provenientes da crise do petróleo eram discutidos nos âmbitos político e econômico, o conceito de greenwashing se fortalecia em meio aos estudos de comunicação, marcas e sociedade (ATHANASIOU, 1996). Aos esforços científicos em comunicação, o termo era e ainda é relevante, porque envolve a construção de uma camada discursiva dissimulada sobre as práticas comerciais, reconhecendo que os apelos da sustentabilidade são estímulos potentes ao consumo.

Se as estratégias de greenwashing, portanto, surgem no contexto da emergência de demandas de mercado por empresas ambientalmente responsáveis, vive-se na conjuntura contemporânea fenômeno semelhante: na tentativa de chamar a atenção de público consumidor ávido por representações mais acuradas da realidade social, marcas constroem discursos publicitários repletos do signo da diversidade. No entanto, enquanto algumas propostas são bem recebidas, uma vez que parecem representar um avanço na construção discursiva do imaginário sobre os corpos e as identidades sociais, muitas fazem emergir a dúvida: há mesmo a construção de uma cultura da diversidade no ambiente empresarial ou apenas iniciativas superficiais que maquiam a realidade nada diversa da marca? Isto é, há, de fato, preocupação marcária com a diversidade ou apenas diversitywashing?

Entende-se que, embora a temática da diversidade esteja em pauta (HOFF, 2009; SILVA; GONÇALVES, 2017), possibilitando que, por exemplo, indivíduos negros estejam mais frequentes nas imagens publicitárias (SACCHITIELLO, 2018), na verdade esta iniciativa não avança da superfície discursiva, uma vez que apenas $4,7 \%$ dos cargos executivos das 500 maiores empresas brasileiras são ocupados por pessoas negras e somente 3,9\% das empresas oferecem alguma forma de ação afirmativa para aumentar a presença negra no ambiente de trabalho (SCRIVANO, 
2016). Essa realidade é repetida na conjuntura de outras minorias ${ }^{3}$, como mulheres (BOCCIA, 2018), idosos (LAPORTA; CAVALLINI, 2018) e pessoas com deficiência (LISBOA, 2018).

Ao compreender, entretanto, a importância da identificação destas discrepâncias para a localização da estratégia discursiva no plano das táticas de diversitywashing, propõe-se aqui um aprofundamento da discussão e do domínio conceitual do termo, ainda carente de problematização científica. Parte-se do pressuposto de que não somente a maquiagem da diversidade se manifesta nesta discrepância, como ela pode ser inscrita no próprio domínio textual e imagético da estratégia publicitária. Entende-se que a perspectiva da diversidade se tornou uma dimensão da performance marcária de si, na qual estão impressas dinâmicas interacionais que dão à audiência o poder sobre, especialmente, suas percepções. Nesse sentido, a marca é inserida no plano das interações sociais, no qual não basta reconhecer-se em uma identidade, mas gerenciar as impressões identitárias que causa no outro (GOFFMAN, 1985).

Sendo assim, este trabalho busca problematizar o conceito de diversitywashing, compreendendo suas dimensões complexas e dependentes dos efeitos de sentido de suas estratégias dentro das percepções da audiência. Inserindo a marca no campo interacional, propõe-se aqui um olhar conceitual sobre estas táticas sob a égide da noção de "coerência expressiva” (SÁ; POLIVANOV, 2012), compreendendo que a identidade de marca "diversa" se constitui enquanto projeto de si (GIDDENS, 2002), em um constante e flexível gerenciamento das impressões que causa nos seus públicos (GOFFMAN, 1985).

3 Entende-se minorias aqui sob a luz sociológica, que pressupõe "coletividades que são discriminadas e estigmatizadas, consubstanciando um quadro de subordinação cultural, política ou socioeconômica a um grupo de domínio, independentemente do número de sujeitos que a compõem em relação à totalidade populacional” (RONDON FILHO, 2013, p. 269), isto é, grupos que ocupam lugares inferiores nas relações de poder cotidianas. 


\section{Mídia e diversidade}

Na esteira de ativismos sociais de mídia livre e de alterglobalização - a exemplo da Cúpula Mundial pela Sociedade da Informação de Genebra (2003) e Tunísia (2005) e, mais recentemente, Primavera Árabe e o Occupy Wall Street (2011), - movimentos sociais contemporâneos, fortalecidos pelas novas ferramentas, erguem suas barricadas contra racismo, xenofobia, estereótipos, sexismo, homofobia e outras violações, reivindicando estruturas sociais mais democráticas. São dinâmicas que desconfiam das estruturas políticas institucionalizadas, mas também fazem um forte questionamento à mídia, buscando construir novas versões dos fenômenos sociais. Nesse sentido, afirma Castells (2012, p. 23), "[...] a disputa de poder fundamental é a batalha pela construção de significados nas mentes", ou seja, uma disputa de narrativa voltada para, segundo o autor, reprogramar as instituições sociais para valores mais democráticos.

No que se refere à mídia tradicional como instituição, é necessário ter em mente o potencial de sua estrutura na normatização cotidiana de valores sociais. Entendida como a profissional da construção narrativa da verdade social pública, a grande responsável pela massificação de informações nas sociedades populosas contemporâneas, torna-se fundamental colocá-la sob a lente analítica de como ela conduz a construção de um inconsciente coletivo. Na medida em que o desconhecido sobre a alteridade é mediado pelos discursos midiáticos, portanto, é fundamental exercitar o olhar crítico atento sobre o condicionamento ou a legitimação de visões de mundo e qual seu impacto na estruturação de sociabilidades contemporâneas - pacíficas, mediadoras de tolerância ou conflitivas, promotoras de exclusão social. Isso é importante, por exemplo, no que se refere aos estereótipos, supergeneralizações construídas socialmente e que são colocadas como arquétipos de determinados grupos sociais, limitando seu significado e a interpretação social sobre o outro (MERSKIN, 2011).

A construção própria de mensagens destinadas ao público massivo dialoga com uma normatização de percepções, reforçando cotidianamente 
o que é compreendido como "normal" ou "desejável”, numa relação muito mais negociada e sedutora, do que impositiva. Trata-se da força reprodutora da violência simbólica de padrões ideais (BOURDIEU, 1989) que, na mesma medida em que estabelece o que é normal, estabelece também o que não é. Assim, discutir estereótipos de mídia é entender as maneiras com que a visão das pessoas é construída sobre os Outros e como a sua marginalização se torna imperceptível ou banalizada no ambiente da mídia. Esses construtos sociais, transmitidos como sendo a "verdade", são concedidos socialmente e reproduzidos institucionalmente em várias esferas, de modo que as percepções de mundo da cultura dominante se vendem como algo natural, óbvio, unanimemente acordado, definindo, assim, as crenças, rituais e os atos numa ordem social.

É através da reprodução de padrões limitados, por exemplo, sobre gênero, raça, classe, sexualidade e religião que arquétipos (visões multidimensionais, símbolos fluidos de personalidade) são transformados em estereótipos (signos unidimensionais e concretizados sobre a Alteridade), sendo potencialmente capazes de difundir valores que justifiquem o ódio coletivo, a perseguição e atrocidades políticas contra determinados grupos (MERSKIN, 2011). Assim, o contato cotidiano com mensagens midiáticas estereotipadas reproduz e reforça socialmente preconceitos - uma antipatia baseada numa generalização distorcida e inflexível, uma atitude avessa ou hostil a uma pessoa que pertence a um grupo simplesmente por ela pertencer a este grupo - e discriminação - o comportamento que resulta do preconceito, envolvendo tratamento injusto aos indivíduos, baseado em algumas características estigmatizadas, como raça, classe, gênero, idade, etnia, religião, naturalidade, orientação sexual, visões políticas, possuir deficiência, etc.

Por se tratar de um sistema excludente e perpetuador de conflitos sociais, iniciativas que indicam sua superação costumam ser comemoradas pelos ativistas ávidos por uma transformação social. Por isso que, conteúdos disruptivos, alternativos e questionadores podem ser infinitamente compartilhados, apropriados e utilizados como uma luz de 
representação mais verdadeira em meio a uma estereotipagem normatizada. São ideias que, atreladas a um consumo contemporâneo de mídia marcado pela complementaridade de informações entre os diversos tipos de meios, se reforçam o suficiente para conquistar poder de disputar narrativas com os valores normativos das mídias tradicionais.

Estas iniciativas, no entanto, fazem emergir vieses críticos de análise que tentam compreender de que maneira a apropriação mercadológica de pautas sociais pode interferir em sua coerência essencial. Ou seja, é indispensável se ter em mente que a estrutura produtiva é dinâmica e força os atores ali presentes a se adaptarem, como uma lógica própria da competitividade. Utilizar-se da causa da diversidade para aproximar-se do público consumidor pode não ser o suficiente para disfarçar a ausência desta representatividade também na mão de obra que é empregada para a produção deste conteúdo.

Afinal, poderia o subalterno falar? A ele é de fato autorizada a escuta? (SPIVAK, 2010). Quem são essas alteridades tão invisíveis ou preconcebidas historicamente ao conteúdo midiático e que agora parecem curiosamente interessantes ao olhar dominante? Haveria, segundo Stuart Hall, um fascínio do pós-modernismo global para com o exótico da diferença: sejam elas sexuais, raciais, culturais e, sobretudo, étnicas. E ele se pergunta se estaria essa reaparição da "proliferação da diferença" relacionada com a fascinação ocidental com os corpos de mulheres e homens negros de outras etnias (HALL, 2003, p. 150). Ainda que nutra esse fascínio pelo exótico, e a busca pelo atendimento à demanda dos consumidores, é possível se perceber uma negociação com os valores dominantes que, volta e meia, se rearticulam numa resistência agressiva à diferença e a possibilidade do risco ao seu privilégio exclusivista. A apropriação pela normatividade tende a integrar a diversidade por via de sua adaptação, correção e ajuste, especialmente quando essa produção passa pelas mãos dos mesmos grupos sociais que sempre dominaram esses conteúdos. 


\section{Autenticidade percebida e as (in)coerências expressivas da marca}

Uma das chaves de observação relevantes para avançar na presente análise é a percepção de autenticidade das construções subjetivas e os processos de validação identitária que são continuamente mobilizados no contexto interacional e podem auxiliar na compreensão das interações comunicacionais entre públicos e marcas. Parte-se do pressuposto de que, mesmo ao construir discursos empresariais e mercadológicos, estes sujeitos marcários estariam subordinados a aparatos relacionais semelhantes àqueles aos quais os indivíduos seriam submetidos, abrangendo táticas de construção de si, negociações identitárias, percepções de alteridade e legitimação, assim como as problemáticas que emergem das relações de poder.

Sob a perspectiva sociológica, a autenticidade seria um construto negociado, em um processo de autorreflexão (GIDDENS, 2002) assujeitado aos trâmites interacionais. Não seria, portanto, a autenticidade um fenômeno concreto, mas uma abstração dependente do retorno social, isto é, "o conceito de autenticidade deve ser entendido não enquanto verdade ontológica, mas como uma 'história partilhada”, construída pelo ator e negociada com os outros (SÁ; POLIVANOV, 2012, p. 581), em um sistema contínuo de legitimação e deslegitimação.

A esta percepção de autenticidade identitária, Sá e Polivanov (2012) dão o nome de "coerência expressiva", ou seja, a constância subjetiva que os indivíduos buscam nos outros e em si mesmos para a validação de quem são e de quem são seus interagentes. Contradições comportamentais e intensas transformações poderiam produzir efeitos deslegitimadores, definindo para os indivíduos maior ou menor "competência social como agentes da interação” (SMITH, 2006, p. 97-98). Sendo assim, o objetivo final da construção identitária seria, portanto, "saber se será acreditado ou desacreditado" (GOFFMAN, 1985, p. 231).

Constituinte de processos interacionais elementares, este regime de validação da autenticidade é reforçado pelas dinâmicas da cultura digital e das materialidades contemporâneas. Boyd (2008) aponta para quatro 
propriedades fundamentais do contexto digital que podem modular os limites e as potencialidades das interações que ali se inserem: persistência, buscabilidade, replicabilidade e audiências invisíveis. A persistência seria a marcação do prolongamento dos atos de fala, em contraposição à efemeridade dos contatos face a face, uma vez que nestes ambientes o registro do discurso é facilitado (POLIVANOV; CARRERA, 2019); a buscabilidade seria um desdobramento da persistência, uma vez que à medida que as mensagens podem ser registradas, elas também podem ser acessadas com agilidade em pequenos cliques de busca; a replicabilidade, por sua vez, seria a facilidade da reprodução da mensagem em contextos e públicos diferenciados; chegando ao pressuposto das audiências invisíveis, conceito que admite a impossibilidade, no ambiente digital, de controlar e mensurar qual é o alcance e a audiência daquilo que se diz. A mediação da materialidade digital, portanto, é contundente para os sistemas interacionais nestes ambientes, sobretudo em comparação com espaços de conversação face a face.

Sendo assim, esse contexto digital contemporâneo permitiria mais recursos materiais para a validação identitária e comunicacional dos indivíduos e, como se quer discutir aqui, inclusive das marcas. Se, portanto, no contexto dos indivíduos, podem ser chamados de "rupturas performáticas" (POLIVANOV; CARRERA, 2019) os desencaixes entre a comunicação de si e os comportamentos sociais ou as fissuras localizadas entre as intenções identitárias e aquelas que as circunstâncias interacionais e materiais permitem, na conjuntura marcária os efeitos dessas lacunas são intensificados pelo cinismo já previsto e solidificado nas relações entre consumidor e comunicação empresarial.

Nesse sentido, se no contexto dos indivíduos, as rupturas performáticas implicam em gerenciamentos de si e das situações, em um processo de tentativa de controle do que se mostra e do que se esconde, isto é, do cenário teatral dos papéis sociais, no qual se define o que é exposto ao público e o que deve ser mantido nos bastidores (GOFFMAN, 1985); se nestes processos interacionais, o que está em jogo é a reputação identitária dos sujeitos, implicando em manutenção da autoestima 
social, do pertencimento e da saúde psicológica; no caso da conjuntura das marcas, o que está em jogo é sua imagem corporativa, que implica em gerenciamento de uma identidade em prol da permanência mercadológica e da fuga constante dos penosos gerenciamentos de crise. Dessa forma, a percepção das rupturas performáticas se manifesta, na conjuntura das marcas, em percepção de "washing", ou seja, em dissimulação percebida ou evidente incoerência expressiva. Nesse sentido, todo o aparato discursivo e operacional que envolve o funcionamento da empresa (por ex., publicidade, pontos de venda, embalagens, produtos, parceiros, fornecedores, funcionários e processos de contratação) pode ser utilizado como reforço ou empecilho para a manutenção da sua coerência expressiva.

Para avançar neste debate, portanto, são discutidos aqui os seis traços mais comuns de incoerência expressiva, no contexto do atributo da diversidade, que podem fazer a marca cair na percepção de "diversitywashing".

\section{Os seis traços do Diversitywashing no contexto das marcas}

A percepção de diversitywashing se dá enquanto efeito de sentido, isto é, depende diretamente não somente das intencionalidades da marca, mas das decodificações que emergem das suas audiências. Não se intenta aqui, portanto, discutir sobre a suposta veracidade das mensagens ou muito menos sobre qual seria a "real" intenção das empresas ao adotarem o discurso da diversidade, mas perceber quais os rastros comunicacionais e comportamentais que as marcas oferecem ao público para que este as localize como atuantes desta prática. Assim, são elencados aqui seis traços comuns de diversitywashing: representações inadequadas, atribuição de neutralidade, bastidores contraditórios, diversidade limitada, comportamentos incoerentes e vida passada. 


\section{Representações inadequadas}

Uma vez que a comunicação publicitária é um dos modos de construção de identidade marcária que menos implicam em transformações estruturais da empresa, manifestar apoio a causas da diversidade parece um simples empreendimento. No entanto, a falta de compreensão das narrativas diversas que compõem cada corpo ali utilizado para fins comerciais, além do pouco esforço em busca desse discernimento crítico a respeito das suas ideias criativas, contribui para a construção de discursos publicitários muitas vezes superficiais e, sobretudo, problemáticos e estereotipados.

É o caso da campanha "Somos Todos Paralímpicos" desenvolvida pela agência de publicidade Africa para a Vogue, mostrando os atores Paulo Vilhena e Cléo Pires como atletas amputados. O contrassenso na ideia de representatividade desta peça foi alvo de críticas na internet alcançando o topo dos Trending Topics na época (agosto de 2016), ${ }^{4}$ pois ela optou por "dar visibilidade" a atletas com deficiência, retirando exatamente estes sujeitos das peças publicitárias e colocando em seus lugares dois corpos padronizados com "deficiências" construídas via edição de imagens.

Outro exemplo é a campanha "Be true to your pleasure" da Magnum protagonizada por transexuais, travestis e drag queens. Ao associar o sorvete e o ato de comê-lo aos rituais de sensualidade impressos nos corpos ali expostos, a marca recai sobre o desconhecimento das diferenciadas narrativas vivenciadas por estes corpos (PELÚCIO, 2005); sobre uma hipersexualização já cristalizada, que impede o acesso destas pessoas a outros espaços profissionais senão à prostituição (JIMENEZ; ADORNO, 2009).

Estes exemplos, portanto, demonstram a problemática comum das representações inadequadas nas propostas publicitárias e fazem emergir debates relevantes sobre os limites possíveis da compreensão sobre as narrativas de sujeitos que não fazem parte da produção criativa e da

4 Informação disponível em: https://oglobo.globo.com/esportes/campanha-com-atores-paralimpicos-gera-polemica-cleo-pires-se-defende-19987262. Acesso em: 30 abr. 2019. 
aprovação das peças. Se há no contexto da criação publicitária e na gestão das agências de publicidade uma predominância de homens heterossexuais, de classe média alta (SACCHITIELLO; LEMOS, 2016; MAIA, 2018) e brancos (DOURADO, 2015), assim como é a mesma a realidade dos cargos de chefia das empresas brasileiras (IBGE, 2014, 2016; GOMES, 2018), a iniciativa pelo aprofundamento da compreensão sobre aquele que se representa sob a égide da diversidade deveria ser um esforço amplificado.

\section{Atribuição de neutralidade}

A atribuição de neutralidade a corpos específicos se manifesta na escolha de alguns sujeitos para representarem o padrão, compondo um pano de fundo supostamente invisível para a marcação dos corpos que seriam "diferentes". Esse tipo de traço é comum nas campanhas publicitárias que propõem uma representação racial "diversa”. Em anúncios que intentam representar indivíduos diferentes e sugerem estar cientes da pluralidade de raças na conjuntura brasileira, deixam escapar que a diversidade se materializa no não branco e o branco se torna invisível em sua racialização. Ou seja, em geral, quando permitem a existência de indivíduos de outras raças em suas campanhas, essa permissão se manifesta em um ou dois modelos em meio a uma maioria branca, corroborando para a acepção de que há uma "certeza intemporal" (FRANKENBERG, 2004, p. 310) e uma "visibilidade não-marcada" (MACHADO, 2018) da branquitude.

Em dezembro de 2016, a modelo negra Deddeh Howard expôs, em projeto intitulado Black Mirror, ${ }^{5}$ a realidade das campanhas de grandes marcas e sua associação com agências de modelo. Recriando diversas fotografias de campanhas famosas em que modelos brancas protagonizavam, Deddeh desejava mostrar os modos do racismo publicitário e as problemáticas da visão desracializada da branquitude: "Even though I was told by those agencies that I have an amazing look and wish they

5 Ver: http://secretofdd.com/?p=2703. 
could represent me, they already have a black model. Besides having an abundance of white models" (HOWARD, 2016). ${ }^{6}$ Com a denúncia, a modelo descortinou a rotina produtiva da publicidade e realçou de forma contundente a "suposta neutralidade da identidade racial branca que faz com que grande parcela da sociedade tenha privilégios, mas não os perceba" (SHUCMAN, 2014, p. 92). Essa neutralidade pode ainda ser percebida nos anúncios abaixo:

Figura 1 - Atribuição de neutralidade racial.

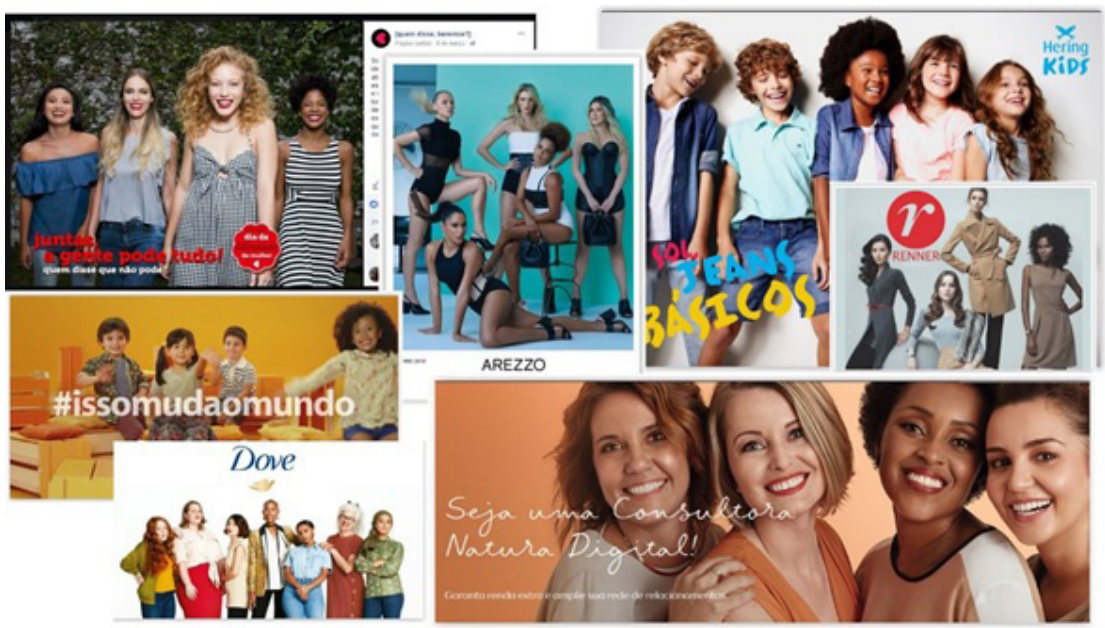

Fonte: Coleta em ambiente digital marcário (sites e mídias sociais, como Facebook e Instagram, da Quem Disse Berenice, Arezzo, Hering Kids, Itaú, Dove, Natura e Renner)

Embora a concepção de neutralidade nasça deste contexto racial, ela pode se manifestar na concepção de que há corpos neutros e outros não, deixando evidente que o diferente é aquele que não corresponde ao padrão normativo de existência da contemporaneidade: branco, magro, heteronormativo, jovem e sem deficiências. Nesse sentido, se não há equivalência representacional e alguns corpos se arvoram em

6 "Mesmo me dizendo que eu tinha um visual incrível e que adorariam poder me contratar, estas agências diziam que já tinham uma modelo negra. Embora tivessem uma abundância de modelos brancas" (tradução nossa). 
invisibilidade, pouco se realiza em torno da suposta transformação enunciativa da publicidade em torno da diversidade, e o que se vê é mais uma manifestação de incoerência expressiva, uma vez que se constrói uma maquiagem discursiva diversa em primeiro plano que é desvelada em sua padronização em um olhar mais atento; ou seja: diversitywashing.

\section{Bastidores contraditórios}

Em maio de 2019, a loja Três, empresa de moda com lojas no Rio de Janeiro e em São Paulo, que se apresenta sob o slogan "Por trás de peças, pessoas", exibe em suas etiquetas o rosto da costureira de cada peça e tem em seu quadro de vendedoras mulheres negras de cabelo crespo, teve que explicar por que esse discurso não se manifestava em suas práticas cotidianas (GONZALEZ, 2019). De acordo com o apurado pelo Portal Universa, o cotidiano na empresa, na verdade, era repleto de racismo, gordofobia e assédio moral dos donos e sócios da empresa. Após a rápida repercussão negativa em redes sociais, a marca publicou uma nota afirmando: "Nosso apreço pela diversidade nunca foi de fachada, como agora nos acusam".

O termo "fachada", empregado pela nota da Loja Três, admite a compreensão dos trâmites que regem o diversitywashing, ou seja, pressupõe uma construção identitária da marca que se apresenta para apreciação do público e outra que a deslegitima se for descoberta. Nesse sentido, a teoria goffmaniana a respeito das interações sociais cotidianas propõe a metáfora do teatro, dividindo a vida social em palco e bastidores, isto é, em espaço de exposição de si e em espaço de ocultamento. Analista das interações face a face, Goffman postulou que todo ator social tem como ponto de partida a representação que se apresenta à sua frente, mas a compreensão e os comportamentos se dão não somente pelo conteúdo do que se diz, mas a partir daquilo que se deixa escapar (GOFFMAN, 1985).

A quebra deste sistema de montagem encenada por aquele que assiste a representação é chamada de "intromissão inoportuna" (GOFFMAN, 1985, p. 192), isto é, quando a plateia entra nos bastidores da 
representação e desmascara o ator por conhecer os elementos da sua vida que podem prejudicar a manutenção do teatro da vida social. Nesse sentido, manter a coerência expressiva seria gerenciar estes elementos para que sejam apenas legitimadores do processo identitário ou evitar que a plateia acesse os elementos contraditórios.

A Loja Três manifestou um traço comum de incoerência expressiva porque, obviamente não apresentava, em seu cotidiano laboral, aquilo que comunicava em prol de lucro e posicionamento mercadológico. Usando o valor simbólico da diversidade, a marca pareceu praticar apenas diversitywashing.

\section{Diversidade limitada}

Este traço dialoga com as noções de expressões transmitidas e expressões emitidas, da perspectiva goffmaniana, uma vez que são ações significantes do processo de gerenciamento de si relevantes para a manutenção do quadro representativo que se deseja. De acordo com Goffman (1985), as primeiras são aquelas de caráter proposital que, por meio de signos conhecidos por sua plateia, fazem eficiente a ação comunicativa. As segundas, por sua vez, incluem movimentos que parecem sintomáticos, não intencionais do ator, e que podem trazer a impressão de que há outros sentidos para aquela informação que fora assim transmitida.

A C\&A e a marca estadunidense Plus Size Baby protagonizaram casos de diversidade limitada recentemente. Em 2017, a loja de departamento brasileira lançou uma campanha com o objetivo de "promover empoderamento" (IZQUIERDO, 2016), com textos que diziam "sou negra, sou loira", "sou menina, sou menino" e "sou gorda, sou sexy". Este último texto acompanhava uma fotografia da modelo Malu Mendes, autodenominada de "curvy model". No entanto, a repercussão da campanha foi negativa pela escolha de uma modelo curvilínea, mas não representativa das mulheres, de fato, gordas. Já a Plus Size Baby, em abril de 2019, fez um post no Twitter com o texto "\#bigsize \#curvygirls Sexy Lace Panties for Plus Size Women”, com uma fotografia de um corpo magro que esticava a peça para mostrar seu tamanho. Nesses casos, 
portanto, o discurso da diversidade e da valorização dos corpos diversos se dá no plano das expressões intencionais. No entanto, deixam escapar, isto é, "emitem" exatamente o contrário do que desejavam, com um movimento significante que revela uma proposta de diversidade muito limitada.

No contexto dos sujeitos negros, esse traço da diversidade limitada já é bem conhecido. Marcas preferem ilustrar a negritude em suas campanhas com corpos de negros de pele clara e traços pouco negroides (GOMES, 2006). Há, comumente, uma tentativa de embranquecimento do negro como modo de tornar palatável sua existência nesse espaço discursivo de poder. Assim, é o corpo miscigenado (preferencialmente mais branco do que preto) que interessa à publicidade, aquele representante perfeito das dinâmicas do colorismo (NORWOOD; FOREMAN, 2014) e representado pela figura da "mulata": aquela mulher que preserva algumas características negras, mas está "a um passo da branquitude" (CRAVEIRO; CARVALHO, 2017, p. 65). Nesse sentido, embora envelopadas por um aparente enaltecimento do discurso da diversidade, estas escolhas denunciam a incoerência expressiva destas marcas, que emitem como efeito de sentido de si a ideia de praticantes de diverstywashing.

\section{Comportamentos incoerentes}

Em março de 2016, a C\&A lançou a coleção "Tudo lindo \& misturado" em um vídeo publicitário que apresentava um modelo masculino colocando um vestido, numa intenção discursiva genderless. No entanto, embora a campanha tenha causado furor pela proposta de vanguarda, rapidamente foi deslegitimada pelo público, que expôs a contradição da marca no seu próprio aparato comunicacional e de marketing: a divisão de gênero feminino e masculino continuava em todos os outros espaços da empresa, como no site e nas lojas, assim como a nova coleção não considerava em seus tamanhos a possibilidade de, realmente, as peças serem misturadas, como afirmava o slogan (GIUSTI; PAUL, 2016).

Diferente do traço de diversitywashing que pressupõe a entrada nos bastidores da representação (bastidores contraditórios), aqui a 
incoerência expressiva se fundamenta no próprio comportamento empresarial que se coloca em evidência, isto é, não há uma intromissão inoportuna da plateia, mas uma discrepância na representação de si que a marca apresenta em seus aparatos comunicacionais (como ponto de venda, site e publicidade). São comportamentos intencionais que, por si mesmos, contradizem e deslegitimam a representação identitária desejada, produzindo a percepção de inautenticidade: "A campanha chama Tudo Lindo \& Misturado, mas quando você vai comprar as peças vê que são belas roupas, masculinas e femininas. Só. O próprio anúncio sugere essa troca mais como uma diversão" (CORRÊA, 2016).

Desse modo, a C\&A manifesta prática de diversitywashing, uma vez que não assume "narrativas biográficas coerentes" (GIDDENS, 2002) nem mantém escolhas discursivas que evidenciem uma coerência expressiva em prol de uma rotina identitária, isto é, uma continuidade da proposta de representação que demonstre certa estabilidade na construção de si (SÁ; POLIVANOV, 2012). Essa coerência é um construto de planejamento minucioso e anterior à representação, isto é, os atores devem ser "prudentes e circunspectos ao representar o espetáculo, preparando-se antecipadamente para prováveis contingências e explorando as oportunidades restantes" (GOFFMAN, 1985, p. 223). Esse pressuposto não foi considerado pela C\&A, que continuou apresentando campanha com a proposta de moda sem gênero, como no anúncio para o Dia dos Namorados do mesmo ano, mas em suas lojas perpetuava e ainda perpetua a separação bem definida entre masculino e feminino.

\section{Vida passada}

Em março de 2017, no contexto brasileiro, a Skol apresenta sua campanha Reposter, ${ }^{7}$ que marcaria o reposicionamento da marca de cerveja em prol, agora, de narrativas publicitárias mais inclusivas e diversas. Reconhecendo seu passado machista, que impregnava seus anúncios de mensagens de hipersexualização feminina, a Skol propõe neste

7 Ver vídeo publicitário Reposter: https://www.youtube.com/watch?v=g_8fnMtbdso. 
momento a reformulação dos seus antigos cartazes por ilustradoras feministas. Pouco tempo depois, a marca lança a campanha Skolors, que apresentava uma edição limitada de embalagens com "as cores de nossa pele", ${ }^{8}$ trazendo latas de cores diferentes para simbolizar a diversidade racial do Brasil.

Com uma repercussão majoritariamente positiva, sobretudo no ambiente digital (SILVA e GONÇALVES, 2017), a marca de cerveja, então, se "apropria do social" numa tentativa de apagamento do seu passado discursivo, que, fundamentalmente, reforçava padrões de opressão, sobretudo em relação à objetificação feminina (BRAGAGLIA, 2019, p. 86). Nesse sentido, optando agora por essa "ideologia de consumo" (BRAGAGLIA, 2019, p. 95) que enaltece corpos, sujeitos e narrativas de existências diversas, a Skol conseguiria, de fato, dissipar do imaginário do seu público a associação da marca a discursos discriminatórios ou seria constantemente relembrada, em um processo de contínua verificação da autenticidade das suas novas iniciativas?

No âmbito do gerenciamento das situações sociais e das representações de si, pode-se dizer que "a vida passada e o curso habitual das atividades de determinado ator contêm [...] fatos que, se fossem introduzidos durante a representação, desacreditariam ou, no mínimo, enfraqueceriam as pretensões relativas a sua personalidade" (GOFFMAN, 1985, p. 192). Esse resgate de comportamentos anteriores pode ser continuamente mobilizado, como forma de deslegitimar alguma estratégia identitária vigente, como pode ser visto no comentário abaixo feito por um usuário do Facebook:

8 Ver vídeo publicitário Skolors: https://www.youtube.com/watch?v=mQx_VmCQu5w. 
Figura 2 - Usuário do Facebook relembra passado contraditório da Skol e atesta a necessidade de coerência expressiva duradoura a partir do reposicionamento da marca.

\section{(1) março de 2017 : $\cdots$ \\ A tal cerveja redonda foi lançada em 1967. Quase 50 anos de propaganda escrota e agora todo mundo apaga esse histórico dando biscoito pra marca por causa de algumas campanhas que tem alcance sobretudo digital e segmentado. Não parabenizo a marca não, parabenizo as mulheres feministas que pressionaram e estão mudando a economia. Quem sabe em 2067, se continuar assim, dá pra parabenizar a cervejaria. \\ 63 comentários 11 compartilhamentos}

Fonte: Facebook.

Considerando que as práticas de diversitywashing se manifestam no plano das percepções, a brusca transformação identitária da marca pode demandar um tempo para que o público assimile sua nova construção de si. Este público pode recorrer, sempre que possível, como fruto de sua desconfiança e com o intuito de deslegitimar a representação marcária vigente, à "vida passada" da marca. Nesse sentido, o contexto digital ainda favorece esse movimento, uma vez que deixa registrado cada comportamento anterior do sujeito marcário, pelas facilidades do atributo da "buscabilidade" (BOYD, 2008). Dessa forma, até que a marca traga consistência comportamental, estabelecendo novas rotinas identitária e narrativas biográficas coerentes com esta nova performatização de si, a qualquer momento pode ser relembrada de fatos da sua vida passada, causando constrangimentos pelo efeito de sentido do diversitywashing.

\section{Considerações finais}

Ao aproximar a realidade identitária da marca às dinâmicas de construção de si dos indivíduos, a discussão aqui proposta expõe um olhar 
alternativo àqueles que em geral buscam compreender as estratégias de marca apenas sob o viés dos seus objetivos de mercado. Nesse sentido, noções como autenticidade e coerência expressiva, comuns nos estudos sobre interações sociais, podem ser importantes operadores analíticos para o entendimento das relações muitas vezes conflituosas entre intenção comunicativa de marca, expectativas da audiência e efeitos de sentido que emergem destas conexões.

Entende-se aqui que o conceito de diversitywashing dialoga com pressupostos sociológicos já estabelecidos para o estudo da vida social dos indivíduos, uma vez que insere disputas simbólicas entre os efeitos do que se diz e os efeitos do que se pratica, em um jogo constante de legitimação e deslegitimação dos discursos de marca, assim como nas negociações interacionais cotidianas. Dessa forma, a proposta aqui apresentada visa articular conceitualmente a noção de diversitywashing sob esse aparato teórico-metodológico, construindo um mapeamento primário para a compreensão das suas manifestações.

No contexto da comunicação midiática em relação ao conceito de diversidade, é importante reconhecer, ainda, que quando o processo de mercadorização tem como objetivo tão somente a venda e o lucro, o pressuposto essencial tende a ser esvaziado e os cidadãos poderão ter seus valores instrumentalizados, bem como suas histórias de vida expropriadas. A estrutura produtiva faz atores individuais normativos terem que se adaptar, isso pode ser visto como um primeiro avanço, mas apenas quando de fato esses espaços forem ocupados pelos corpos diversos, narrativas podem ser disputadas, e novas histórias contadas.

\section{Referências}

ATHANASIOU, T. The age of greenwashing. Capitalism Nature Socialism, v. 7, n. 1, p. 1-36, 1996.

BATISTA, L; LEITE, F (Org.). O negro nos espaços publicitários brasileiros: perspectivas contemporâneas em diálogo. São Paulo: Escola de Comunicações e Artes/USP: Coordenadoria dos Assuntos da População Negra, 2011.

BOCCIA, S. IBGE: número de mulheres em cargos de liderança caiu nos últimos 4 anos. Época Negócios, 2018. Disponível em: https://epocanegocios.globo.com/colunas/ 
Bolsa-de-Valores/noticia/2018/09/ibge-numero-de-mulheres-em-cargos-de-lideranca-caiu-nos-ultimos-4-anos.html. Acesso em 16 abr. 2019.

BOURDIEU, P. O poder simbólico. Rio de Janeiro: Bertrand, 1989.

BOYD, D. Why Youth Love Social Network Sites: The Role of Networked Publics in Teenage Social Life. In: BUCKINGHAM, D (Ed.). Youth, identity, and digital media. Cambridge: The MIT Press, 2008. p. 119-142.

BRAGAGLIA, A. P. A apropriação do social pela publicidade: Skol Reposter e suas ideologias de consumo. Signos do Consumo, v. 11, n. 1, 2019.

CASTELLS, M. Redes de Indignación y esperanza. Madrid: Alianza, 2012.

CORRÊA, F. Moda sem gênero? Estadão, 24 de março de 2016. Disponível em: https:// emais.estadao.com.br/blogs/moda-na-pratica/moda-sem-genero/. Acesso em: 25 mai. 2019.

CRAVEIRO, C.; CARVALHO, C. A um passo da branquitude: o que dizem os corpos das mulatas brasileiras? Interfaces Científicas-Humanas e Sociais, v. 6, n. 2, p. 65-76, 2017.

DOURADO, D. A presença dos negros nas agências de publicidade: um olhar para a liderança das agências do Brasil. Disponível em: https://daniladourado.com. br/2015/10/25/a-presenca-dos-negros-nas-agencias-de-publicidade/. Acesso em: 2 abr. 2019.FRANKENBERG, R. A miragem de uma branquitude não marcada. In: WARE, V. (Org.), Branquidade, identidade branca e multiculturalismo. Tradução de V. Ribeiro. Rio de Janeiro: Garamond 2004, p. 307-338.

GIDDENS, A. Modernidade e identidade. Rio de Janeiro: Jorge Zahar Ed., 2002.

GIUSTI, I.; PAUL, F. Tentamos criar looks sem gênero com a nova coleção da C\&A. Buzzfeed. Disponível em: https:/www.buzzfeed.com/br/irangiusti/testamos-roupas-cea. Acesso em: 25 mai. 2019.

GOFFMAN, E. A representação do eu na vida cotidiana. Petrópolis: Vozes, 1985.

GOMES, A. P. O negro em propagandas televisivas de produtos de higiene e beleza: reformulações da imagem e transformações sociais. Caxambu: Anpocs, 2006.

GOMES, E. Brancos são maioria em empregos de elite e negros ocupam vagas sem qualificação. Gl. 14 de maio de 2018. Disponível em: https:/gl.globo.com/economia/ noticia/brancos-sao-maioria-em-empregos-de-elite-e-negros-ocupam-vagas-sem-qualificacao.ghtml. Acesso em: 25 mai. 2019.

GONZALEZ, M. Racismo, gordofobia e assédio moral: funcionários denunciam marca carioca. Portal Universa, 20 mai. 2019. Disponível em: https://universa.uol.com.br/ noticias/redacao/2019/05/20/racismo-gordofobia-e-assedio-moral-funcionarios-denunciam-marca-carioca.htm. Acesso em: 25 mai. 2019.

HALL, S. Que "negro" é esse da cultura popular negra? In: HALL, S. Da Diáspora: identidades e mediações culturais. Belo Horizonte: Editora UFMG, 2003.

HOFF, T. M. C. et al. O corpo imaginado na publicidade. Cadernos de Pesquisa, v. 1, n. 1, p. 9-64, 2009. 
IBGE. Demografia das empresas. Estudos e pesquisas. Informação econômica, IBGE, Coordenação de Metodologia das Estatísticas de Empresas, Cadastros e Classificações. Rio de Janeiro: IBGE, 2014.

Pesquisa Nacional por Amostra de Domicílios (PNAD), 2016. In: SILVEIRA, D. Cai a participação de mulheres em cargos gerenciais no Brasil em 2016, aponta IBGE. G1. 7 mar. 2018. Disponível em: https://gl.globo.com/economia/concursos-e-emprego/ noticia/cai-a-participacao-de-mulheres-em-cargos-gerenciais-no-brasil-em-2016-aponta-ibge.ghtml. Acesso em: 25 mai. 2019.

IZQUIERDO, T. C\&A se envolve em polêmica em campanha com modelo plus size. Veja SP. 7 de setembro de 2016. Disponível em: https://vejasp.abril.com.br/blog/beleza-de-blog/c-038-a-se-envolve-em-polemica-em-campanha-com-modelo-plus-size. Acesso em: 26 mai. 2019.

LAPORTA, T.; CAVALLINI, M. Idosos ampliam espaço no mercado de trabalho, mas só 1/4 tem carteira assinada. G1, 2018. Disponível em: https://gl.globo.com/economia/ concursos-e-emprego/noticia/2018/1 1/18/idosos-ampliam-espaco-no-mercado-de-trabalho-mas-so-14-tem-carteira-assinada.ghtml. Acesso em: 16 abr. 2019.

LISBOA, A. P. Deficiência x Mercado trabalho. Correio Braziliense, 2018. Disponível em:https:/www.correiobraziliense.com.br/app/noticia/eu-estudante/tf_carreira/2018/04/01/tf_carreira_interna,670201/deficiencia-x-mercado-trabalho.shtml.

Acesso em: 16 abr. 2019.

MACHADO, E. S. Visibilidade não marcada da branquitude: discursos de mulheres brancas acadêmicas. Revista da Associação Brasileira de Pesquisadores/as Negros/as (ABPN), v. 10, p. 375-398, 2018.

MAIA, F. Entrevista concedida a Cláudia Penteado: Baixa presença de negros na publicidade é uma questão histórica e social. Disponível em: http://propmark.com.br/mercado/ baixa-presenca-de-negros-na-publicidade-e-uma-questao-historica-e-social. Acesso em: 25 mai. 2019.

MERSKIN, D. Media, minorities and meaning. New York: Peter Lang Publishing, 2011. NORWOOD, K. J.; FOREMAN, V. S. The ubiquitousness of colorism. In: Color matters: Skin tone bias and the myth of a postracial America, p. 9-28, 2014.

POLIVANOV, B.; CARRERA, F. Rupturas performáticas em sites de redes sociais: um olhar sobre fissuras no processo de apresentação de si a partir de e para além de Goffman. Intexto, Porto Alegre, UFRGS, n. 44, p. 74-98, jan./abr. 2019.

RONDON FILHO, E. B. Polícia e minorias: Estigmatização, desvio e discriminação. Dilemas - Revista de Estudos de Conflito e Controle Social, v. 6, n. 2, p. 269-293, 2013.

SÁ, S.; POLIVANOV, B. Auto-reflexividade, coerência expressiva e performance como categorias para análise dos sites de redes sociais. Contemporanea - Revista de Comunicação e Cultura, v. 10, n. 3, p. 574-596, 2012.

SACCHITIELLO, B. Cresce o número de protagonistas negras em comerciais. Meio e Mensagem, 2018. Disponível em: https:/www.meioemensagem.com.br/home/ 
comunicacao/2018/12/13/cresce-o-numero-de-protagonistas-negras-nos-comerciais. html. Acesso em: 16 abr. 2019.

; LEMOS, A. Mulheres são 20\% da criação das agências. Meio e Mensagem. Dis-

ponível em: https:/www.meioemensagem.com.br/home/comunicacao/2016/01/12/ mulheres-sao-20-porcento-da-criacao-das-agencias.html. 12 jan. 2016. Acesso em: 25 mai. 2019.

SCRIVANO, R. Negros e mulheres ocupam menos de $20 \%$ dos cargos altos das empresas. O Globo, 2016. Disponível em: https://oglobo.globo.com/economia/negros-mulheres-ocupam-menos-de-20-dos-cargos-altos-das-empresas-19277091. Acesso em: 16 abr. 2019.

SILVA, T.; GONÇALVES, E. Diversidade de corpos na publicidade: o contexto interpretativo nas campanhas Skolors e Reposter da Skol no Facebook. Tríade: Comunicação, Cultura e Mídia, SP, v. 5, n. 10, p. 95-112, dez. 2017.

SMITH, G. Erving Goffman. New York: Routledge, 2006.

SPIVAK, G. Pode o subalterno falar? Belo Horizonte: Editora UFMG, 2010, 133 p.

\section{Sobre as autoras}

Fernanda Carrera - Professora da Escola de Comunicação da Universidade Federal do Rio de Janeiro (UFRJ). Professora do Programa de Pós-graduação em Comunicação da Universidade Federal Fluminense (UFF) e do Programa de Pós-graduação em Estudos da Mídia (PPgEM/UFRN). Líder do grupo de pesquisa LIDD - Laboratório de Identidades Digitais e Diversidade (UFRJ). Doutora em Comunicação pela Universidade Federal Fluminense (UFF). Mestre em Comunicação e Cultura Contemporâneas pela Universidade Federal da Bahia (UFBA). No presente artigo, a autora participou da concepção do desenho da pesquisa, do desenvolvimento da discussão teórica, da coleta e interpretação dos dados, da redação do manuscrito e da revisão do texto.

Chalini Torquato - Professora Adjunta na Escola de Comunicação da Universidade Federal do Rio de Janeiro - ECO/UFRJ. Doutora pelo Programa de Pós-Graduação em Comunicação e Cultura Contemporâneas da Universidade Federal da Bahia (PósCom/UFBA), onde também concluiu seu mestrado. É integrante do Grupo de Pesquisa em Políticas e Economia da Informação e da Comunicação (PEIC/UFRJ), do Grupo de Estudos Formas de Habitar o Presente. É coordenadora geral do projeto de extensão Semana da Diversidade da 
UFRJ. No presente artigo, a autora participou do desenvolvimento da discussão teórica, da coleta e interpretação dos dados, da redação do manuscrito e da revisão do texto.

Data de submissão: 15/06/2019

Data de aceite: 15/12/2019 